\title{
Challenging the Inevitable: Anatomy of a Suicide at the Royal Court Theatre London
}

\author{
FRANCESCA RAYNER
}

Title: Anatomy of a Suicide. Author: Alice Birch. Director: Katie Mitchell. Set designer: Alex Eales. Costume designer: Sarah Blenkinsop. Lighting designer: James Farncombe. Composer: Paul Clark. Sound designer: Melanie Wilson. Associate director: Lily McLeish. Assistant director: Grace Gummer. Casting director: Amy Ball. Production manager: Marty Moore. Costume supervisor: Lucy Walshaw. Company manager: Joni Carter. Deputy stage manager: Sophie Rubenstein. Assistant stage manager: Louise Quaeermain. Stage management work placement: Robert Fletchr. Chaperone: Grace Osborne. Cast: Gershwyn Eustache Jnr. (Jamie), Paul Hilton (John), Peter Hobdaay (Dan/Dave/Felix/Luke/Nick), Adelle Leonce (Bonnie), Sarah Malin (Daisy/Diane/Emma/Esther/Karen/May), Jodie McNee (Jo/Laura/Lola), Hattie Morahan (Carol), Kate O'Flynn (Anna), Sophie Pettit, Vicki Szent-Kirallyl (Anna/Daisy/Louise), Dickson Tyrell (Tim/Toby/Steve/ Mark). Place and date of premiere: Royal Court Theatre (Jerwood Theatre Downstairs), 3 $3^{\text {rd }}$ June, 2017.

As the title suggests, this performance was not for the faint-hearted. In another collaboration with director Katie Mitchell following the 2015 Ophelia's Zimmer, playwright Alice Birch has written a remarkable piece about inherited suicide along the maternal line. In her play, three generations of women feel the pressure to continue living when they would often prefer to be dead and have to decide to what extent the existence of children makes the thought of suicide unbearable. They feel the pressure that comes with the knowledge that their own mothers committed suicide and wonder whether this means that this is inevitably their own destiny. This sense of the maternal legacy as a burden leads the youngest of the three to consider sterilisation rather than pass this suicidal tendency onto a child. Instead, she decides to sell the family home where her mother died and there is the suggestion that she may thorough this action have broken the chain. In perhaps one of the most moving changes of scenery I have witnessed in the theatre, this attempt to free herself was accompanied by the sudden raising of the dark, hospital-like background which had been present throughout the performance to reveal a house in the 


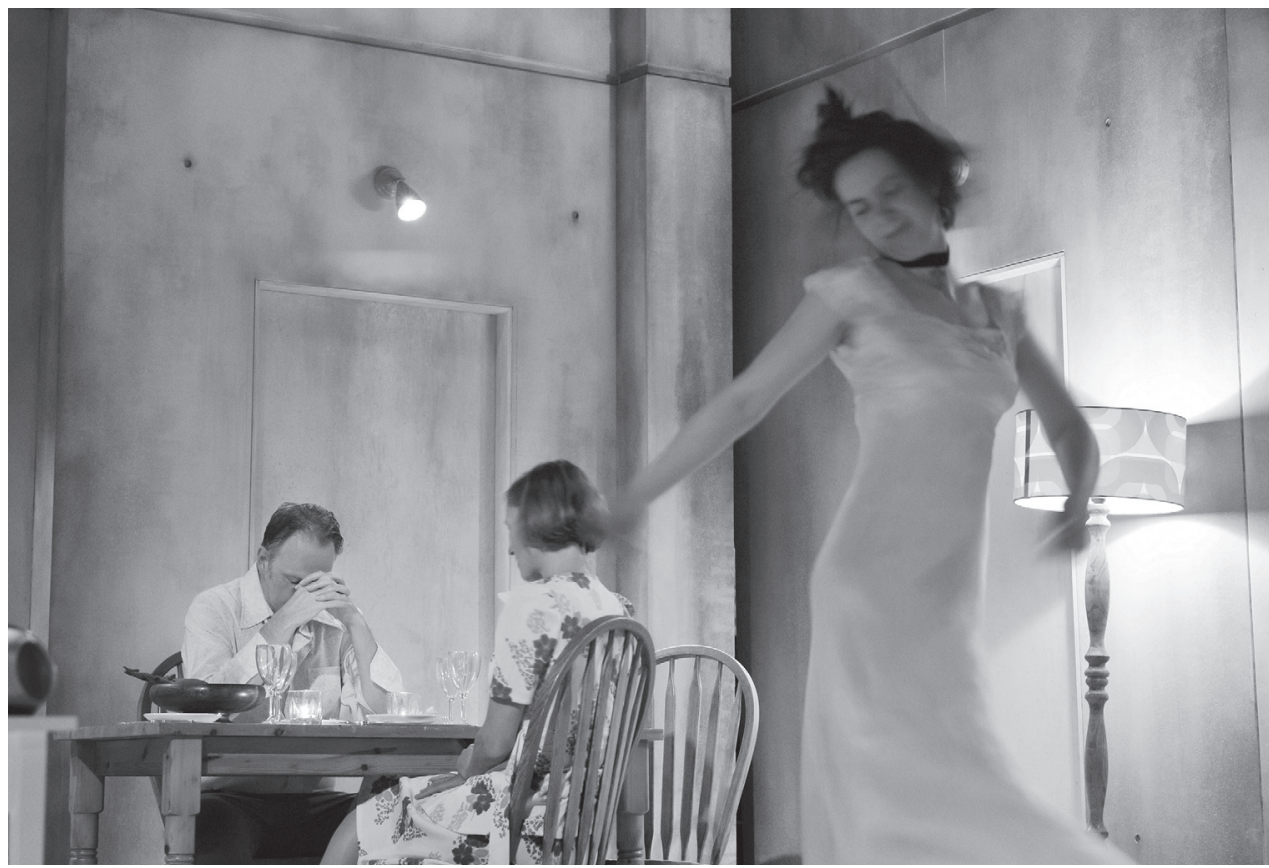

ANATOMY OF A SUICIDE, DE ALICE BIRCH, ENC. KATIE MITCHELL (DICKSON TYRELL, SARAH MALIN, KATE O'FLYNN), 2017, [F] STEPHEN CUMMISKEY

country with light streaming through the window. After nearly two hours of bare walls and lights, this scene change came as a welcome relief and a hopeful indication of the ways in which vicious cycles can be broken.

When staging Sarah Kane's Cleansed in 2016, Katie Mitchell had already been confronted with the question of suicide. In this performance, rather than stage the stories of the three women consecutively in chronological order, Mitchell worked with the interconnections in the play to tell the stories simultaneously onstage. In this way, narratives from the 1970's, the 1990's and the 2030's were interwoven together and threw light on each other, although it should be said that the representation of the near future in the third of these narratives differed little from what we would expect to find in the present day. The three actresses who played the main roles were onstage throughout and the supporting cast who played the members of their families, doctors, children and lovers dressed them and brought on props as the years passed. The actresses stripped down to their underwear and held their arms up for these costume changes as if uncertain of the extent to which they controlled their unfolding lives. 


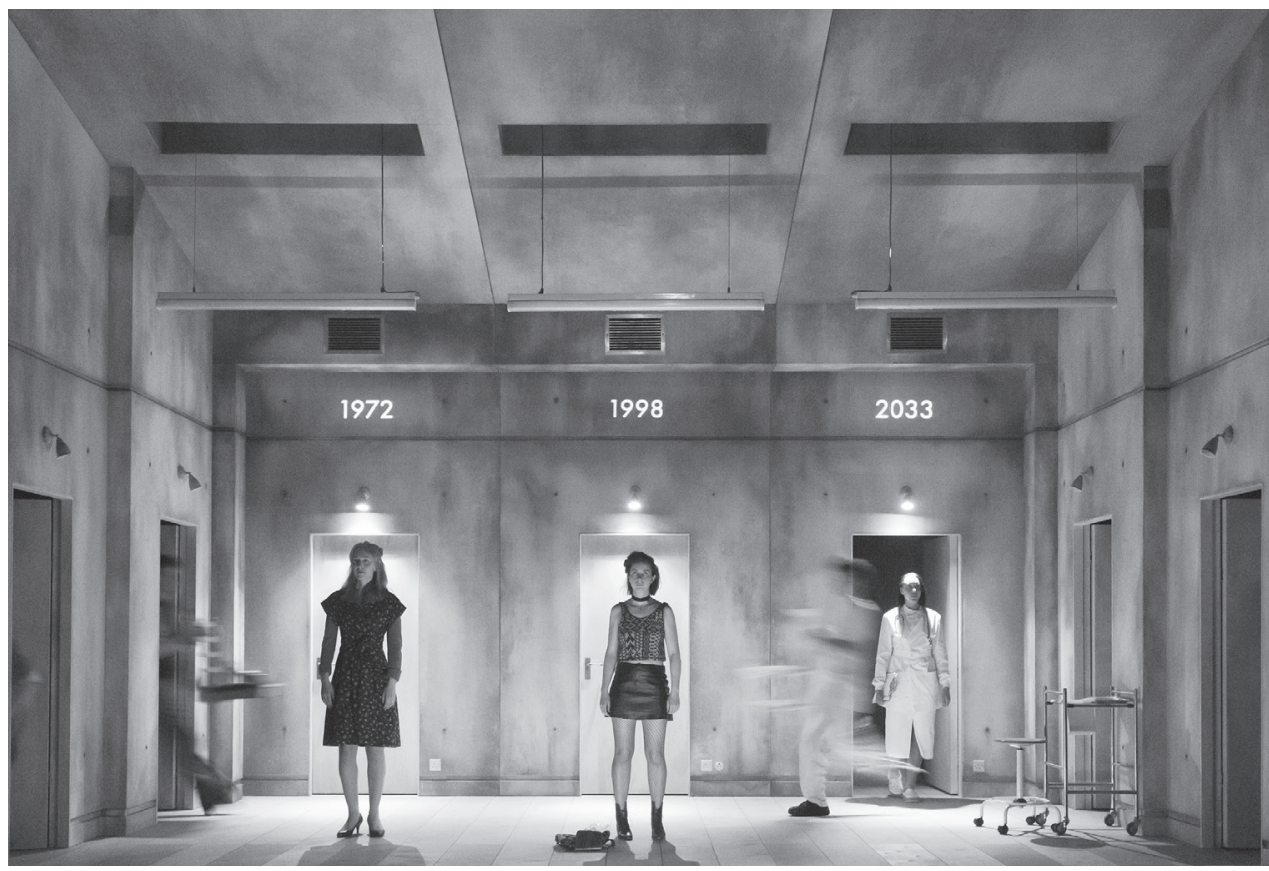

ANATOMY OF A SUICIDE, DE ALICE BIRCH, ENC. KATIE MITCHELL (HATTIE MORAHAN, KATE O'FLYNN, ADELLE LEONCE), 2017, [F] STEPHEN CUMMISKEY

As always with Katie Mitchell, there was no room for lazy or imperfectly present performers in this production. As well as having to remember and execute multiple prop and costume changes, spoken dialogues were often interconnected, requiring very precise timing in order, for example, for two of the actresses to say the same phrase at the same time in different time periods or for a line in one story to follow on immediately from a line in another. In this sense, the performance expertly staged the sense that each generation influenced those who came after them in often profound ways. Anna (Kate O'Flynn), for instance appeared both as a child and a grown woman in the performance, embodying this connection. Nevertheless, there was also a strong sense of differences in the lives of the three women and of the changes brought about by social, political and medical transformations. An hesitant moment of lesbian suggestiveness in the portrayal of Carol (Hattie Morahan) in the 1970's, for instance became a rather tormented lesbian relationship in the 2030 life of Bonnie (Adelle Leonce). Doctors recommended electroconvulsive treatment for Carol in the 1970's while nobody made such a suggestion to Bonnie, the competent woman doctor from the near future, although the stresses of 
working in a contemporary hospital created their own strain on her life. Midway between the two, Anna in the 1990's escaped to a commune after a drug overdose and parented a mixed-race child. Immediately afterwards, however, she electrocuted herself in the bath, unlike Carol who sought to hold on to life for as long as she could for the sake of her daughter. The characters around the women veered between protectiveness and non-understanding. The sister of Carol's husband John, Emma (Sarah Malin) for instance, suggested having another baby might be a cure for her unwillingness to live, while John's frank account of Carol's death on a railway line to the young Anna seemed deliberately cruel in its stark retelling of the end of her mother's life. As such, the performance was a courageous way of creating discussion about a question that has invariably been misunderstood (with people saying she/he should just get over it) or swept under the carpet as a taboo subject. The staging was consistently understated, enabling the intensity of the piece to emerge clearly in a very non-judgemental way. Crucially, both text and direction reinforced the distinction between a tendency towards and the certainty of suicide, resisting narratives of the inevitable while emphasizing significant continuities.

The three actresses created three very different, individual, women with a tragic bond binding them together. Carol's moments of calm and hope were combined with explosive moments of rage and despair. Anna's comic turns contrasted with her moments of isolation while Bonnie's professional competence hid her fear of committing herself to a long-term relationship. As in all the best tragedies, there were moments where it seemed as if each tragedy might be averted and others where it seemed inevitable. The two suicides, one narrated and one shown, were genuinely shocking even when they were expected, while the constant changes of clothes and setting gave a sense of courageous, if futile, attempts to keep the possibility of suicide at bay. Throughout, the strength of the writing and the present-centeredness of the performers were well-served by a director who was aware of when to intervene more directly in order to emphasize the way the stories were interconnected and when to leave performers and audiences simply to make up their own minds about how the stories were linked. As the notion of anatomy suggests, the performance sought to go beyond the surface reality of the women's lives without judging their actions. In this way, the performance was an intense, beautifully-written meditation on a difficult theme, staged with sensitivity, empathy and absolute precision. 